\title{
Investigation of Dielectric and Ferroelectric Properties of Titanium Doped $\mathrm{AgNbO}_{3} \mathrm{Ceramic}$
}

\author{
Aditya Joshi $^{1 *}$ S. C. Bhatt ${ }^{1} \cdot$ Manish Uniyal $^{1}$ • S. C. Nautiyal ${ }^{2}$ \\ ${ }^{1}$ Department of Physics, HNB Garhwal University (A Central University), Srinagar 246174, India \\ ${ }^{2}$ Department of Physics, Govt. P.G. College, Maldevta, Raipur, Dehradun 248008, India \\ *Corresponding Author Email Id: madityajoshi@gmail.com
}

Received: 2.8.2021; Revised: 16.9.2021; Accepted 19.9.2021

CSociety for Himalayan Action Research and Development

\begin{abstract}
The electrical properties of the titanium doped $\mathrm{AgNbO}_{3}$ system are defined in this paper. In the modified system, doping moderately replaced $\mathrm{Nb}^{5+}$ with $\mathrm{Ti}^{4+}$ ion where the ceramics are prepared using solid-state reaction technique. The dielectric characteristics were examined at frequencies ranging from $1 \mathrm{kHz}$ to $100 \mathrm{kHz}$. The dielectric value of the modified systems increased substantially while the P-E curve emerged with a value of relatively increased spontaneous polarization.
\end{abstract}

Keywords: $\mathrm{Ag}(\mathrm{Nb}, \mathrm{Ti}) \mathrm{O}_{3} ; \mathrm{AgNbO}_{3}$; Dielectric properties; Ferroelectric properties;

\section{Introduction}

Silver niobate $\left(\mathrm{AgNbO}_{3}\right)$ is most exciting ferroelectric material, which has a polarization value of $52 \mu \mathrm{C} \mathrm{cm}^{-2}$ (Fu et al. 2007) has been extensively studied as a parent substance for electronic applications (Lines et al. 2001). At room temperature, the $\mathrm{AgNbO}_{3}$ has skewed perovskite structure exhibits 6 reversible transitions in phase related to structural change, as confirmed by the dielectric dispersion. The number of multiple phase transitions associated with structural change in $\mathrm{AgNbO}_{3}$ is due to the cations ordering i.e. A-site (Ag) and B-site (Nb) (Sciau et al. 2004; Levin et al. 2009). A previously supported result of the centrosymmetric $\mathrm{Pbcm}$ structure, which specifies antiferroelectricity in $\mathrm{AgNbO}_{3}$, was later surpassed by groups of researchers who emphasized the Pmc2 ${ }_{1}$ structure to explain ferroelectricity in $\mathrm{AgNbO}_{3}$ (Yashima et al. 2011; Chang et al. 2012). In perovskite structure of $\mathrm{AgNbO}_{3}$, off centering A-site and B-site cations can be seen, which show strong A-O bonding covalency. According to previous theoretical research the $\mathrm{Nb}$-site of $\mathrm{AgNbO}_{3}$ has ferroelectric ordering, while the Ag-site atom has antiferroelectric ordering. As a base material, a lot of modifications have been done on $\mathrm{AgNbO}_{3}$, where monovalent and pentavalent ions are doped into the $\mathrm{Ag} \& \mathrm{Nb}$ site, respectively. In this present work, we modified the $\mathrm{AgNbO}_{3}$ system with heterovalent titanium $\left(\mathrm{Ti}^{4+}\right)$ cations and examine the electrical properties of the modified system which is expected to be helpful for basic research and application.

\section{Experimental Procedures}

Solid-state reaction technique is used for preparation of the samples. Powdered silver oxide $\mathrm{Ag}_{2} \mathrm{O}$ (99.5\%), niobium pentaoxide $\mathrm{Nb}_{2} \mathrm{O}_{5}$ (99.99\%) and titanium dioxide $\mathrm{TiO}_{2}(99.99 \%)$ were used as a base materials. The lower molecular weight quantity of $\mathrm{TiO}_{2}(\mathrm{x}=0.02,0.04)$ was used for modified $\mathrm{Ag}(\mathrm{Nb} . \mathrm{Ta}) \mathrm{O}_{3}$ system. All the materials first dried at $200{ }^{\circ} \mathrm{C}$ for $2 \mathrm{hrs}$ to remove moisture and weighted in stoichiometric ratio. In next step all the materials manually mixed for $6 \mathrm{hrs}$ and calcined at $850{ }^{\circ} \mathrm{C}$ for 6 hrs. The calcined powder pressed into $10 \mathrm{~mm}$ pallets and sintered for $2 \mathrm{hrs}$ at $1050{ }^{\circ} \mathrm{C}$. XRD is 
used to characterize phase and crystallinity while SEM reveals the surface topography of the prepared samples. Dielectric permeability $(\varepsilon)$ and Deviations in loss tangent $(\tan \delta$ ) were measured for distinct frequency ranges.

\section{Result and Discussion}

\section{Structural Analysis}

The XRD pattern are well correspond to orthorhombic $\mathrm{AgNbO}_{3}$ verifying the emergence of requisite phases ( $\mathrm{Li}$ et al. 2009; Shu et al.2010; Dong et al. 2014; Yang et al. 2015). The relocation of the peak intensity indicates that titanium was properly placed at the target destination. Fig.1 depicts the XRD patterns of the synthesized samples. Tiny marks are recognized as secondary phases which are inevitable regardless of synthesis conditions (Kravchenko et al. 2011).

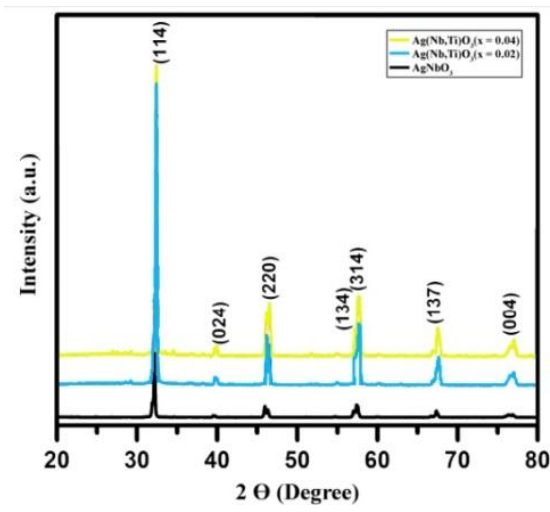

Fig. 1. The XRD graph of the titanium modified $\mathrm{AgNbO}_{3}$.
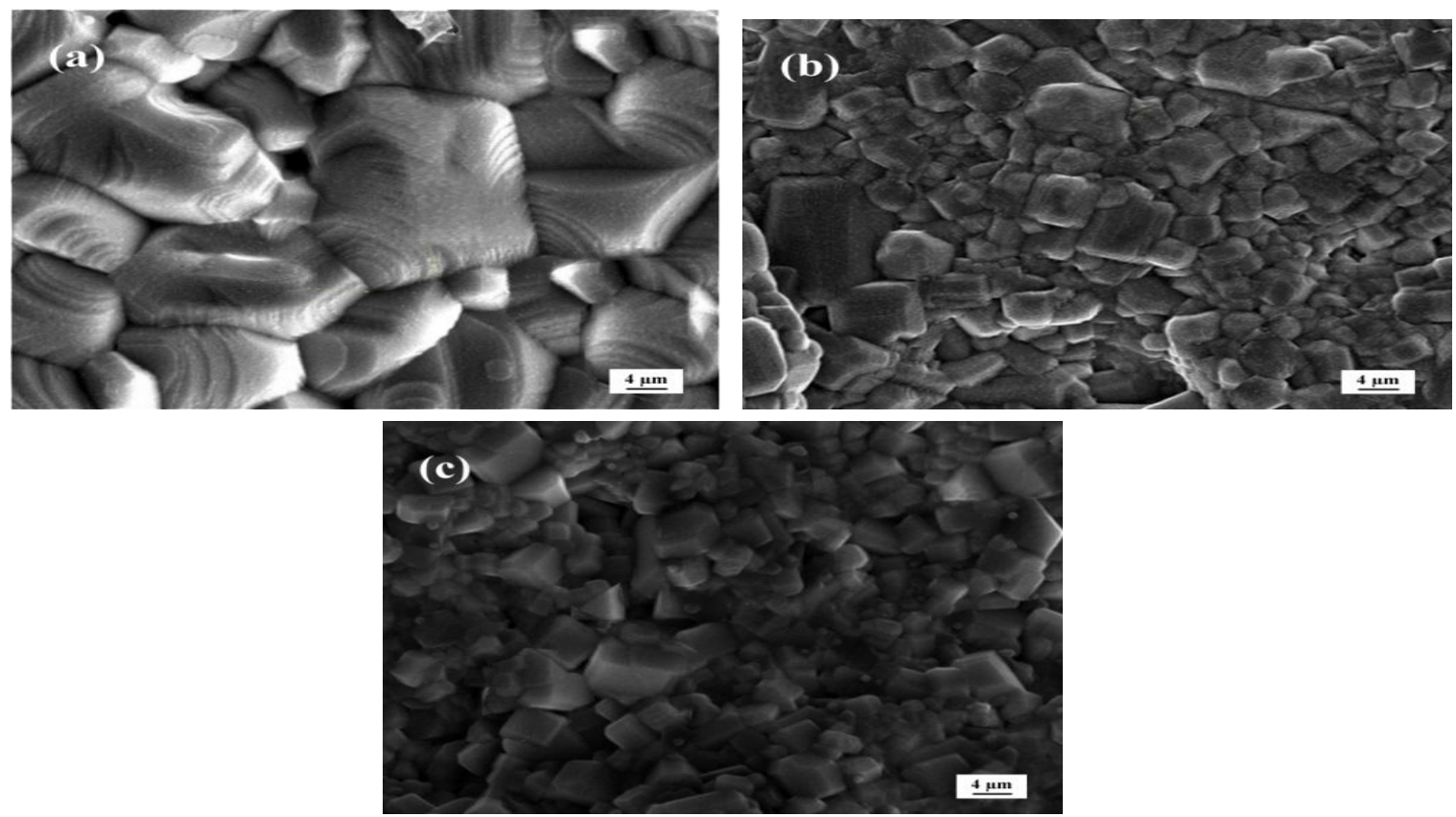

Fig. 2. The SEM image of (a) $\mathrm{AgNbO}_{3}$, (b) $\mathrm{Ag}(\mathrm{Nb}, \mathrm{Ti}) \mathrm{O}_{3}(\mathrm{x}=0.02)$ and (c) $\mathrm{Ag}(\mathrm{Nb}, \mathrm{Ti}) \mathrm{O}_{3}(\mathrm{x}=0.04)$

Titanium replacement has resulted in a reduction in grain size. Fig.2 demonstrates the SEM image of
$\mathrm{AgNbO}_{3}$ and its modified system. The particles in the $\mathrm{AgNbO}_{3}$ sample are polyhedrons that scatter 
non-uniform and vary in size from $1.2 \mu \mathrm{m}$ to $5 \mu \mathrm{m}$. The modified system exhibits non - uniform grain distribution from nano to micro level were grain structure shifted to cube or cuboid form.

\section{Dielectric and Ferroelectric study}

The dielectric dispersion and loss tangent for the modified system are shown in Fig.3. Four dielectric irregularities observed at $80{ }^{\circ} \mathrm{C}, 265^{\circ} \mathrm{C}, 350{ }^{\circ} \mathrm{C}$ and $386{ }^{\circ} \mathrm{C}$. The ferroelectric transition temperature noted near at $70{ }^{\circ} \mathrm{C}$ (Kania \& Miga 2001; Hu et al.2006; Fu et al. 2009; Khan et al. 2012). According to previous report, the $\mathrm{Ag}^{1+}$ ion concentrations influence the variation of the ferroelectric transition temperature peak (Kania et al. 2014).
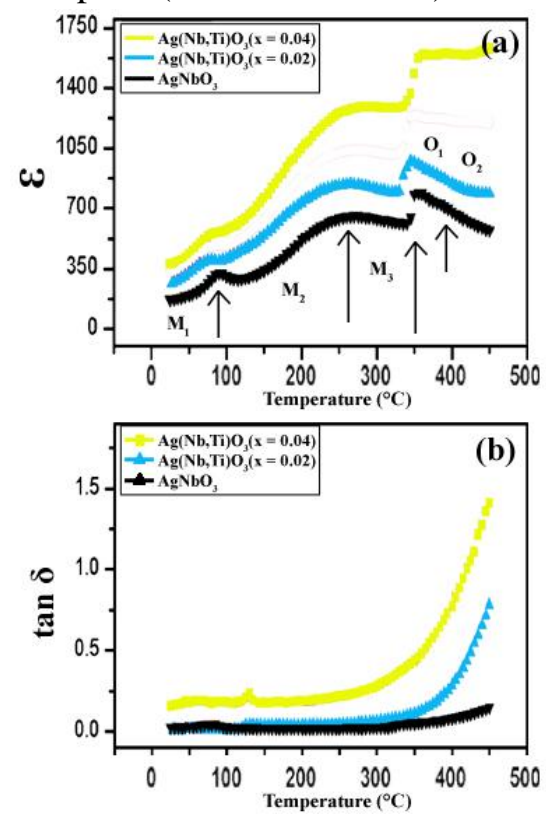

Fig. 3. (a) Dielectric dispersion (b) loss tangent of the titanium modified $\mathrm{AgNbO}_{3}$ at $100 \mathrm{kHz}$ frequency.

The dielectric characteristics of the modified systems show a noticeable improvement. The dielectric irregularity at low $\left(\mathrm{T}_{\mathrm{C}}{ }^{\mathrm{FE}}\right)$ and high $\left(\mathrm{T}_{\mathrm{C}}{ }^{\mathrm{AFE}}\right)$ temperature shifts to the lower and higher temperatures, respectively. The titanium modification increased the dielectric loss observed in increasing rate above the Curie point $\left(\mathrm{T}_{\mathrm{C}}{ }^{\mathrm{AFE}}\right)$ and far below the specified point.
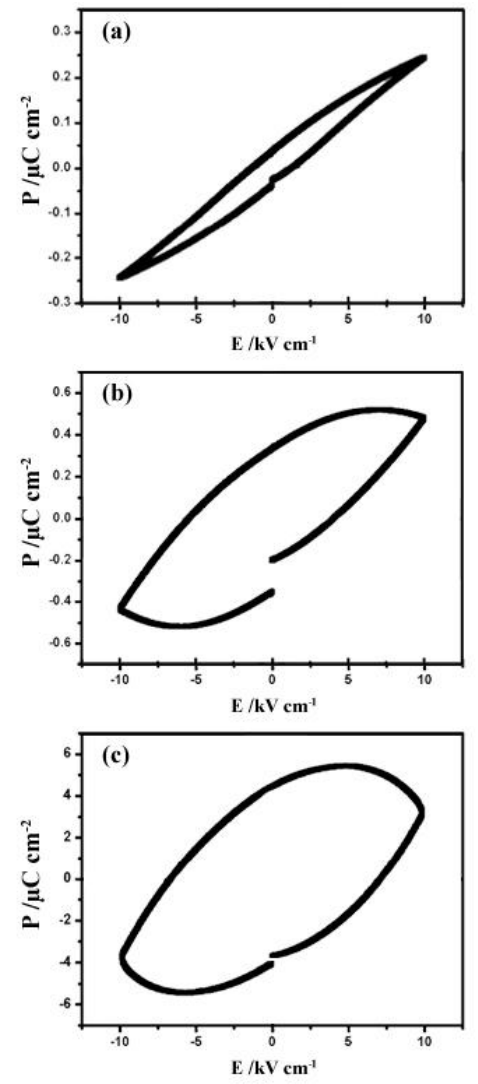

Fig.4. Hysteresis loop of (a) $\mathrm{AgNbO}_{3}$, (b)

$\mathrm{Ag}(\mathrm{Nb}, \mathrm{Ti}) \mathrm{O}_{3}(\mathrm{x}=0.02)$ and $(\mathrm{c}) \mathrm{Ag}(\mathrm{Nb}, \mathrm{Ti}) \mathrm{O}_{3}(\mathrm{x}=$ $0.04)$ for applied field of $10 \mathrm{kV}$.

The $\mathrm{P}-\mathrm{E}$ graph of $\mathrm{AgNbO}_{3}$ and its modified system is shown in the Fig.4. The titanium modification has altered the loop nature. As concentration increases, the slope in the maximum voltage field is continuously rounded and achieves a loss function that increases dielectric constant and polarization.

\section{Conclusion}

The titanium modified $\mathrm{AgNbO}_{3}$ system was successfully prepared by solid-state reaction technique where $\mathrm{Nb}^{5+}$ is replaced by $\mathrm{Ti}^{4+}$ ion. Doping had a major impact on electrical properties of the system. The dielectric value notably increases with an increase in polarization. Furthermore, because of its enhanced electrical properties, the 
titanium doped $\mathrm{AgNbO}_{3}$ ceramics is a versatile material for electro-optic applications.

\section{Acknowledgement}

The authors would like to thank H.N.B Garhwal University for its facilities, as well as Prof. T.C. Upadhyay (HOD, Physics), Mr. Moolchand and Mr. Kuldeep Kumar for their valuable guidance, motivation, and support.

\section{References}

Chang, H., Shang, M., Zhang, C., Yuan, H., \& Feng, S. (2012). Hydrothermal syntheses and structural phase transitions of $\mathrm{AgNbO}$ 3. Journal of the American Ceramic Society, 95(11), 3673-3677.

Dong, H., Chen, G., Sun, J., Feng, Y., Li, C., \& Lv, C. (2014). Stability, durability and regeneration ability of a novel Ag-based photocatalyst, Ag 2 $\mathrm{Nb} 4 \mathrm{O}$ 11. Chemical Communications, 50(50), 6596-6599.

Fu, D., Endo, M., Taniguchi, H., Taniyama, T., \& Itoh, M. (2007). $\mathrm{Ag} \mathrm{Nb} \mathrm{O} \mathrm{3:} \mathrm{A} \mathrm{lead-free}$ material with large polarization and electromechanical response. Applied physics letters, 90(25), 252907.

Fu, D., Itoh, M., \& Koshihara, S. Y. (2009). Dielectric, ferroelectric, and piezoelectric behaviors of $\mathrm{AgNbO} 3-\mathrm{KNbO} 3$ solid solution. Journal of Applied Physics, 106(10), 104104.

Hu, X., Valant, M., \& Suvorov, D. (2006). Phase transitions and dielectric properties of the $\mathrm{Ag}$ $1-\mathrm{x}$ Bi x/ 3 Nb O 3 system. Journal of applied physics, 99(12), 124109.

Kania, A., \& Miga, S. (2001). Preparation and dielectric properties of $\mathrm{Ag} 1-\mathrm{xLixNbO3}$ (ALN) solid solutions ceramics. Materials Science and Engineering: B, 86(2), 128-133.
Kania, A., Niewiadomski, A., Miga, S., JankowskaSumara, I., Pawlik, M., Ujma, Z., ... \& Suchanicz, J. (2014). Silver deficiency and excess effects on quality, dielectric properties and phase transitions of $\mathrm{AgNbO} 3$ ceramics. Journal of the European Ceramic Society, 34(7), 1761-1770.

Khan, H. U., Sterianou, I., Miao, S., Pokorny, J., \& Reaney, I. M. (2012). The effect of Lisubstitution on the M-phases of $\mathrm{AgNbO}$. Journal of Applied Physics, 111(2), 024107.

Kravchenko, O. Y., Gadzhiev, G. G., Omarov, Z. M., Reznichenko, L. A., Abdullaev, K. K., Razumovskaya, O. N., ... \& Verbenko, I. A. (2011). Phase transformations and properties of Ag $1-y \quad \mathrm{NbO} 3-\mathrm{y} / 2 \quad(0 \leq \mathrm{y} \leq 0.20)$ ceramics. Inorganic Materials, 47(8), 919-925.

Levin, I., Krayzman, V., Woicik, J. C., Karapetrova, J., Proffen, T., Tucker, M. G., \& Reaney, I. M. (2009). Structural changes underlying the diffuse dielectric response in $\mathrm{AgNbO}$ 3. Physical Review B, 79(10), 104113.

Li, G., Yan, S., Wang, Z., Wang, X., Li, Z., Ye, J., \& Zou, Z. (2009). Synthesis and visible light photocatalytic property of polyhedron-shaped AgNbO 3. Dalton Transactions, (40), 85198524.

Lines, M. E., \& Glass, A. M. (2001). Principles and applications of ferroelectrics and related materials. Oxford university press.

Sciau, P., Kania, A., Dkhil, B., Suard, E., \& Ratuszna, A. (2004). Structural investigation of $\mathrm{AgNbO} 3$ phases using $\mathrm{x}$-ray and neutron diffraction. Journal of Physics: Condensed Matter, 16(16), 2795.

Shu, H., Xie, J., Xu, H., Li, H., Gu, Z., Sun, G., \& $\mathrm{Xu}, \mathrm{Y}$. (2010). Structural characterization and photocatalytic activity of $\mathrm{NiO} / \mathrm{AgNbO} 3$. 
Journal of Alloys and Compounds, 496(1-2), 633-637.

Yang, L., Liu, J., Chang, H., \& Tang, S. (2015). Enhancing the visible-light-induced photocatalytic activity of $\mathrm{AgNbO} 3$ by loading $\mathrm{Ag} @ \mathrm{AgCl}$ nanoparticles. RSC advances, 5(74), 59970-59975.

Yashima, M., Matsuyama, S., Sano, R., Itoh, M., Tsuda, K., \& Fu, D. (2011). Structure of ferroelectric silver niobate $\mathrm{AgNbO}$. Chemistry of Materials, 23(7), 1643-1645. 